\title{
Highlights from Recent Literature
}

\section{ANALYTICAL}

\subsection{A Portable Cyanide Analyser using Gold Wire Electrodes}

A continuous flow potentiometric analyser for $\mathrm{CN}^{-}$, incorporating multiple gold wire electrodes has been described by M. Sequeira, D.B. Hibbert and P.W. Alexander of the Department of Analytical Chemistry, University of New South Wales, Sydney, Australia (Electroanalysis, 1999, 11, 494-498). The portable apparatus consists of a low-powered peristaltic pump, and a Perspex multicell incorporating six indicator and six reference electrodes connected to an eight channel A/D converter. Real-time data may be displayed on a notebook computer. The system performance was optimized for sample peak heights, reproducibility, working ranges, and calibration slopes. Well-defined peaks and fast response times (with peak widths $<20$ s) were observed using a carrier of $0.1 \mathrm{M} \mathrm{NaOH}$ at a flow rate of $5 \mathrm{~mL} \mathrm{~min}{ }^{-1}$. The repeatability of the electrode response was $2.3 \%(n=5)$. The log-linear range was $0.25-70 \mathrm{ppm}(9.6-2700 \mu \mathrm{M})$ with slopes 96,205 , and $450 \mathrm{mV}$ decade $^{-1}$ for one, three, and six electrodes in series, respectively.

\subsection{Spectrophotometric Determination of Gold(III) with 5-(3-Methyl-2-pyridyl) methylenerbodanine}

Z. Huang, G. Yang, J. Yin and O. Xu of the Department of Chemistry, Yunnan University, Kunming, P.R. China (Yejin Fenxi, 1999, 19, 13-14) have described a method for the spectrophotometric determination of $\mathrm{Au}(\mathrm{III})$, based on the colour reaction of 5-(3-methyl-2-pyridyl) methylenerhodanine (MPMR) with $\mathrm{Au}(\mathrm{III}), \mathrm{A}$ stable complex with the ratio of $1: 2$ was formed by $A u(I I I)$ and MPMR in acid medium in the presence of CTMAB. The absorption maximum of the complex was at 435 $\mathrm{nm}$; the molar absorptivity $6.02 \times 104$, and Beer's law was obeyed at $0-50 \mu \mathrm{g} / 25 \mathrm{~mL}$. The interference of $\mathrm{Cu}^{2+}$ can be masked by EDTA. The method was used for the determination of gold in ore.

\section{CATALYSIS}

\subsection{The Influence of the Gold Content in Nickel Catalysts on the Course of the $\mathrm{CO}+\mathrm{NO}$ Reaction}

With the ever-increasing demands linked with decreasing sulfur levels in gasoline fuels, base metal catalysts have become attractive in alternative pollution control systems (W. Cwikla and D. Nazimek of the Faculty of Chemistry, Marie Curie-Sklodowska University, Lublin, Poland (Adsorpt. Sci. Technol., 1998, 16(10), 773-791). The NiAu catalyst is an interesting alloy for use in the reaction between $\mathrm{CO}$ and $\mathrm{NO}$, partly because of the large difference between the heats of chemisorption of $\mathrm{NO}$ and $\mathrm{CO}$ on the two metals. This paper presents a study of the course of $\mathrm{NO}$ reduction by $\mathrm{CO}$ which additionally made it possible to trace changes in the activity and selectivity of the process for alloys of varied Ni-Au composition and alloys of varied $\mathrm{Pt}-\mathrm{Rh}$ composition.

\subsection{Novel Method for Preparation of a Nanosized Gold Catalyst Supported on Titania}

K. Sayo, S. Deki and S. Hayashi, Department of Chemical Science and Engineering, Kobe University, Japan, J. Colloid Interface Sci., 1999, 212, 597-599) have found that a titania surface was readily modified with nanosized gold particles prepared by the thermal relaxation technique. Adsorption of the gold particles was very rapid, and the adsorbed gold particles distributed independently. Using the two-step calcination of the modified $\mathrm{TiO}_{2}$, the nanosized gold particles were immobilized on the $\mathrm{TiO}_{2}$ surface without size growth or coagulation. The supported gold particles showed lowtemperature catalytic activity for $\mathrm{CO}$ oxidation. The prepared nanosized gold particles interacted with $\mathrm{TiO}_{2}$.

\subsection{Gold Based Composition on a Support of Cerium Oxide and/or ZirconiumOxide as a Catalyst and its Preparation}

P. Marecot and R. Emmanuel of Rhone Poulenc Chimie (French Patent 2771310 A1 990528) have described catalysts based on gold particles (especially with $3 \mathrm{~nm}$ particle size) and particles of other metals (especially platinum group metals) supported on $\mathrm{CeO}_{2}$ and/or $\mathrm{ZrO}_{2}$ which were prepared by selective reduction and precipitation of metal salts on the 
support. The catalysts are suitable for low-temperature oxidation of $\mathrm{CO}$, oxidation or selective hydrogenation of ethylenic and acetylenic hydrocarbons, and treatment of engine exhaust gases.

\subsection{Structural Analysis of Gold on Titania Catalysts by Debye Function Analysis}

Catalysts consisting of $1-3.6 \% \mathrm{Au}$ on $\mathrm{TiO}_{2}$ have been studied by Debye function analysis (D.A.H. Cunningham, W. Vogel, R.M. Torres Sanchez, K. Tanaka and M. Haruta, J. Catal., 1999, 183, 24-31). The structure of gold on titania was found to be predominantly fcc cuboctahedral, with a size distribution between 3 and $4 \mathrm{~nm}$. Gold catalysts prepared by photodecomposition were found to be less active for carbon monoxide oxidation than catalysts prepared by deposition precipitation, and consisted of cuboctahedral particles betwen 1 and $7 \mathrm{~nm}$ in size.

The ability of $\mathrm{Au} / \mathrm{TiO}_{2}$ to catalyse $\mathrm{CO}$ oxidation using fcc cuboctahedral symmetry gold particles, whereas for $\mathrm{Mg}(\mathrm{OH})_{2}$ the icosahedral structure is required, implies that the reaction must take place at the interface between the metal and the support, and that the structures of both the gold particle and the underlying support determine the overall activity.

\subsection{How a Gold Substrate Can Increase the Reactivity of a Platinum Overlayer}

M.O. Pedersen, S. Helveg, A. Ruban, I Stensgaard, E. Laegsgaard, J.K. Norskov and F. Besenbacher, CAMP and Institute of Physics and Astronomy, University of Aarhus, Denmark, Surf. Sci., 1999, 426, 395-409, have studied the growth and chemical reactivity of $\mathrm{Pt}$ on $\mathrm{Au}(111)$ using scanning tunnelling microscopy (STM) and temperature programmed desorption (TPD). Deposition of $\mathrm{Pt}$ at coverages from 0.02 ML (monolayer) up to $2.5 \mathrm{ML}$ on $\mathrm{Au}(111)$ at room temperature initially leads to the formation of a surface alloy, in which $3 \%$ of the gold atoms are replaced by platinum. Subsequent evaporation of platinum leads to island growth with a mixed Pt-Au island composition. The reactivity of the $\mathrm{Pt} / \mathrm{Au}$ system was studied using $\mathrm{CO}$ as a probe molecule.

The stronger bonding of $\mathrm{CO}$ to the first layer of $\mathrm{Pt}$ on $\mathrm{Au}(111)$ was demonstrated compared with the bonding of $\mathrm{CO}$ to clean Pt. The gold substrate therefore very surprisingly increases the $\mathrm{Pt}$ overlayer reactivity. The results can be understood in a simple model, in which the change in the $\mathrm{CO}$ binding energy is directly proportional to the shift of the d-band centre of the metal overlayer. According to this model, the increased reactivity of the $\mathrm{Pt} / \mathrm{Au}(111)$ system should hold for other adsorbates and reactions as well.

\section{CHEMISTRY}

\subsection{Assembly of Phenylacetylene-Bridged Gold Nanocluster Dimers and Trimers}

L.C. Brousseau, J.P. Novak, S.M. Marinakos and D.L. Feldheim, Department of Chemistry, North Carolina State University, Raleigh, NC, USA (Adv. Mater., 1999, 11, 447-449) have prepared phenylacetylenebridged gold nanocluster dimers and trimers of AcS-p$\mathrm{C}_{6} \mathrm{H}_{4}\left[\mathrm{C} \equiv \mathrm{C}-\mathrm{p}-\mathrm{C}_{6} \mathrm{H}_{4}\right]_{5} \mathrm{C} \equiv \mathrm{C}-\mathrm{p}-\mathrm{C}_{6} \mathrm{H}_{4} \mathrm{SAc}$ and $1,3,5-$ $\mathrm{C}_{6} \mathrm{H}_{3}\left(\mathrm{C} \equiv \mathrm{C}-\mathrm{p}-\mathrm{C}_{6} \mathrm{H}_{4} \mathrm{C} \equiv \mathrm{C}-\mathrm{p}-\mathrm{C}_{6} \mathrm{H}_{4} \mathrm{SAc}\right)_{3}$ by pouring an aqueous gold sol into an aqueous ethanol solution of the appropriate phenylacetylene linker. The formation of dimeric and trimeric assemblies was investigated by UV-visible spectroscopy and TEM.

\subsection{Electronic Absorption Spectra of Gold(III) Halide Complexes in Aqueous Solutions}

E.V. Makotchenko, V.I. Malkova and V.I. Belevantsev of the Institute of Inorganic Chemistry, Siberian Division, Russian Academy of Sciences, Novosibirsk, Russia (Russ. J. Coord. Chem., 1999, 25, 282-288) have studied the influence of the ionic medium and concentration of halide ions on the spectra of the solutions containing anionic complexes $\mathrm{AuX}_{4} \cdot \mathrm{solv}^{-}\left(\mathrm{X}=\mathrm{Cl}^{-}\right.$or $\left.\mathrm{Br}^{-}\right)$. Parameters of the individual bands of the ionic complexes in the media studied were obtained. Formation constants of $\mathrm{AuBr}_{5} \cdot \mathrm{solv}^{2-}$ in $5.0 \mathrm{M} \mathrm{NaBr}$ were estimated and used to calculate the spectrum of this complex. The parameters of the individual bands of the tetra- and pentabromide complexes are compared. For the latter, two strong bands occur at $37,000-30,000 \mathrm{~cm}^{-1}$, instead of a single band for the tetrabromide complex.

\section{COATINGS, FILMS, MEMBRANES AND WIRES}

\subsection{Formation of Gold Nanowires Through Self-Assembly During ScanningForce Microscopy}

Gold films with a nominal thickness of 5-40 monolayers were grown on dielectric substrates and imaged by SFM (M. Andersson, A. Iline, F. Stietz and F. Trager, Fachbereich Physik, Universität Kassel, Germany, Appl. Phys. A: Mater. Sci. Process., 1999, 68, 609-614).

The films originally consisted of well-separated or densely packed clusters. During imaging in contact mode, the morphology of the films changed drastically. At low coverage, ie $\theta<10$ monolayers, the well-known stripes originating from mobile clusters, eventually 
accumulated into larger aggregates, were observed. In contrast, at larger coverage, highly ordered structures consisting of one-dimensional wires evolved during scanning. They often were parallel with equal separation, ie well-defined periodicity, over distances of several $\mu \mathrm{m}$. Typically, the wires were 5-10 nm high and 50-100 nm wide.

Investigations of gold films prepared at varying temperature on different dielectric substrates allows the suggestion of a self-assembling mechanism for wire formation in which gold is periodically collected by the SFM tip and redeposited as soon as a critical amount is reached.

\subsection{Molecular Hydrogen Interactions with Discontinuous and Continuous Thin Gold Films}

L. Stobinski, L. Zommer and R. Dus of the Institute of Physical Chemistry, Polish Academy of Sciences, Warsaw (Appl. Surf. Sci., 1999, 141, 319-325) have studied the influence of thin gold film surface nanostructure on hydrogen chemisorption on unsintered gold films at $78 \mathrm{~K}$. Three classes of thin gold films of different thicknesses were chosen for these experiments, ie : (i) very thin, purplish colour, transparent film formed by isolated gold islands, (ii) violet-green colour film formed by gold islands joined together and creating a kind of golden net, (iii) nontransparent, continuous gold film of golden colour. It has been found that hydrogen chemisorption occurs only in the case when the thin gold films are deposited at low temperatures $(78 \mathrm{~K})$ and unsintered.

It has been suggested that this chemisorption occurs on surface gold atoms of low coordination number as a result of formation of $\mathrm{AuH}_{2}$ complexes, similar to the compounds arising from hydrogen interaction with isolated gold atoms.

\subsection{Nanofabrication of Gold Particles in Glass Films by AFM-Assisted Local Reduction}

It has been reported by $\mathrm{H}$. Yanagi and $\mathrm{T}$. Ohno, Faculty of Engineering, Kobe University, Japan, Langmuir, 1999, 15, 4773-4776) that gold nanoparticles can be fabricated in thin glass films using a sol-gel process and atomic force microscopy (AFM). Using a conductive AFM cantilever, local reduction of $\mathrm{Au}$ (III) ions doped in a dip-coated silica/titania gel film generated gold particles embedded at a certain position within the film. The size of the particles was controlled by the voltages applied between the cantilever and an indium-tin oxide coated glass substrate. Scanning the biased cantilever produced gold particles dispersing in the scan area which exhibited a visible absorption spectrum corresponding to the typical surface plasmon band of the nanometerscale gold particles. Further scanning resulted in gold clusters heaped up at the scan area, which gave a redshifted absorption band due to aggregation.

\subsection{Thermal Conductivities of Evaporated Gold Films on Silicon and Glass}

G. Chen and P. Hui, Avimo Group Ltd, Singapore (Appl. Phys. Lett., 1999, 74, 2942-2944) have described four-point probe measurements of the inplane electrical conductivities of electron beamevaporated gold layers of thickness $20 \mathrm{~nm}$ to $2 \mu \mathrm{m}$ deposited on $\mathrm{Si}(100), \mathrm{Si}(111)$, and $\mathrm{BK} 7$ glass substrates. The values of thermal conductivities deduced from these measurements of gold films on glass samples agree well with prediction from the surface and grain-boundary scattering model, but is not so for gold films on silicon samples. Thermal conductivities of gold films were found to be different for samples on hydrofluoric acid etched $\mathrm{Si}(100)$ and $\mathrm{Si}(111)$ substrates, for which surface roughness and microstructures of the gold films were examined to understand the difference in these thermal conductivity results.

\section{COLLOIDS AND NANOPARTICLES}

\subsection{Preparation and Optical Properties of Colloidal Gold Monolayers}

Colloidal gold adsorbed onto positively charged substrates forms a $2 \mathrm{D}$ layer with a maximum coverage of one colloid per $1000 \mathrm{~nm}^{2}$ as shown by optical absorption spectroscopy, small-angle $\mathbf{x}$-ray scattering, and AFM (J. Schmitt, P. Maechtle, D. Eck, H. Möhwald and C.A. Helm, Institut für Physikalische Chemie, Johannes Gutenberg-Universität, Mainz, Germany, Langmuir, 1999, 15, 3256-3266). Positively charged substrates were obtained by either chemisorption of end-group-functionalized silanes or by polycation adsorption. Bulk diffusion controls adsorption onto the gold; thus lower coverages can also be achieved. The optical spectra not only contain information on single colloids but also on their mutual interactions, as well as on the polymeric and solvent environments. Absorption spectra were calculated based on Mie and Maxwell-Garnett theory. The films remain stable on exchange of the external solvent. The local dielectric environment was shown to not only 
influence the position of the absorption band but also, more drastically, the intensity (by a factor of 2.5 ), in agreement with theoretical predictions $( \pm 15 \%)$. Particle aggregation induced by branched polycations causes an additional low-energy absorption peak.

\subsection{Novel Preparation Metbod for Nano-Sized Gold Particles Using $\mathrm{NH}_{2}$-Terminated Polyethyleneoxide}

Nano-sized gold particles dispersed in a composite were prepared by using $\mathrm{NH}_{2}$-terminated polyethyleneoxide (PEO-NH$)_{2}$ as a matrix ( $\mathrm{S}$. Hayashi, K. Sayo, A. Yamada, K. Akamatsu and S. Hayashi, Department of Chemical Science and Engineering, Faculty of Engineering, Kobe University, Japan, J. Colloid Interface Sci., 1999, 214, 123-125). Gold was vapour-deposited onto a melt of $\mathrm{PEO}-\mathrm{NH}_{2}$, and smoothly dispersed into the interior of $\mathrm{PEO}-\mathrm{NH}_{2}$ to form nano-sized gold particles. After cooling the melt to room temperature, a stable solid composite was obtained. The composite readily dissolved in water or organic solvents to produce a stable colloidal solution. The mean size of the gold particles was $3.4 \mathrm{~nm}$, and the content of gold was ca $5 \mathrm{wt} \%$.

\subsection{Monothiols Derived from Glycols as Agents for Stabilizing Gold Colloids in Water: Synthesis, Self-Assembly and Use as Crystallization Templates}

M. Bartz, J. Kuther, G. Nelles, N. Weber, R. Seshadri and $W$. Tremel of the Institut für Anorganische und Analytische Chemie, Johannes Gutenberg-Universität, Mainz, Germany (J. Mater. Chem., 1999, 9, 1121 1125) have demonstrated that tetraethylene glycol $\left(\mathrm{HO}-\left(\mathrm{C}_{2} \mathrm{H}_{4} \mathrm{O}\right)_{4}-\mathrm{H}\right)$ can be monofunctionalized by replacing one of the terminal hydroxy groups with the thiol $\mathrm{SH}$ group. The resulting molecule can be selfassembled on $\mathrm{Au}(111)$ surfaces. Of greater importance is the fact that this molecule allows the simple 1-step preparation of protected, water-soluble gold colloids within a single aqueous phase. Attempts were made to use such protected water-soluble colloids as nucleating seeds around which calcium carbonate can be crystallized.

\subsection{Ligand-Induced Gold Nanocrystal Superlattice Formation in Colloidal Solution}

X.M. Lin, C.M. Sorensen and K.J. Klabunde, Condensed Matter Laboratory Department of Physics, Kansas State University, Manhattan, USA (Chem. Mater.,1999, 11, 198-202) have described an inverse micelle synthesis of narrow size-distributed, ligand-induced gold nanocrystal superlattices (NCSs) in colloidal solution. Several ligands containing thiol, sulfide and amino functional groups were chosen to further modify the surface of the existing gold nanoparticles. Dodecanethiol was proven to be most effective in forming NCSs compared with other ligands. These ligands were chosen because the functional groups they contain have fairly good affinity for the metal surface. It was found that certain ligands added to the colloid induce a spontaneous and self-size-selective NCS formation. The gold NCS structures were directly synthesized in the colloid and their structure and size distribution were studied by TEM and UV-vis spectroscopy.

\subsection{A Simple and Effective Chemical Route for the Preparation of Uniform Nonaqueous Gold Colloids}

M.Y. Han, C.H. Quek, W. Huang, C.H. Chew and L.M. Gan, of the Department of Chemistry, National University of Singapore (Chem. Mater., 1999, 11, 11441147) have described a simple and clean method of producing uniform nonaqueous gold colloids by the chemical reduction of chloroauric acid $\left(\mathrm{HAuCl}_{4}\right)$ using an oxygen-free formamide medium as reducing agent in the presence of the stabilizer poly(vinylpyrrolidone) (PVP), at room temperature. A two-step reaction process to gold particles was suggested from the kinetics. This new and effective chemical route also provides an alternative method for producing other uniform transition-metal particles in nonaqueous solvents.

\section{ELECTROCHEMISTRY}

\subsection{Formation and Accommodation of Gold Atom Clusters and Oxygen Bubbles During Amorphous Anodic Alumina Growtb}

X. Zhou, H. Habazaki, K. Shimizu, P. Skeldon, G.E. Thompson, and G.C. Wood of the Corrosion and Protection Centre, University of Manchester Institute of Science and Technology, UK (Proc. R. Soc. London, Ser. $A, 1999), 455(1982), 385-399)$ have shown that the growth of anodic oxide films on metals and alloys is of both theoretical value, in particular with relation to the mechanism of ionic transport in amorphous materials, and practical interest, especially in the surface treatment of metals and alloys and the use of anodic films in electronics applications. Most previous work has focused on uniform film growth, with formation of either an 
essentially single-layered or a duplex oxide. The present work, employing TEM and Rutherford backscattering spectroscopy, addresses the generation of metallic and gaseous phases in association with the usual film growth, and reveals the ability of the labile amorphous film to accommodate these non-oxide phases. Thus, anodizing of a thin $\mathrm{Al}-0.47 \mathrm{at} \%$ gold alloy, deposited upon an electropolished aluminium substrate, is shown to result in formation of gold atom clusters of ca 1-5 nm size and fine oxygen bubbles, at high pressures, which are contained by the growing amorphous alumina film. The generation of the phases originates from enrichment of gold in a thin layer of the alloy, probably containing gold-rich precursor clusters, during the oxidation of the alloy layer and the subsequent enforced incorporation of gold atom clusters into the anodic film by the electropolishing film on the aluminium. The final clusters are essentially immobile following incorporation into the growing anodic film. At the time of, and briefly after, the incorporation of clusters into the film, gaseous oxygen is produced by oxidation of $\mathrm{O}^{2-}$ ions from the $\mathrm{Al}_{2} \mathrm{O}_{3}$, which occurs at the cluster$\mathrm{Al}_{2} \mathrm{O}_{3}$ interface prior to electrical isolation of the cluster due to its undermining further film growth. The resultant oxygen bubbles generated within the $\mathrm{Al}_{2} \mathrm{O}_{3}$ expand as the film grows, driven by the high gas pressure and assisted by the effective plasticity of the labile amorphous $\mathrm{Al}_{2} \mathrm{O}_{3}$ under the electric field.

\subsection{Photoinduced Electron Transfer at a Gold Electrode Modified with Self-Assembled Monolayer of Fullerene}

A stable anodic photocurrent was observed in the presence of an electron sacrificer when a gold electrode modified with a self-assembled monolayer of $C_{60}$ was illuminated with monochromic light, indicating the generation of a vectorial electron flow from the electron donor to the gold electrode via the excited states of $\mathrm{C}_{60}$. The work was carried out by $\mathrm{H}$. Imahori, T. Azuma, S. Ozawa, H. Yamada, A. Ajavakom, H. Norieda, Y. Sakata and K. Ushida at the The Institute of Scientific and Industrial Research, Osaka University, Japan (Chem. Commun., 1999, 557-558).

\subsection{Contact Electroresistance Method for In Situ Studies of Metal Surfaces in Electrolytes: Adsorption of Hydroxyl Ions and Sub-Monolayer Electrooxidation of Gold}

The contact electroresistance (CER) of gold has been studied as a function of potential $(\mathrm{E})$ in acidic, neutral, and alkaline solutions by V.A. Marichev at the Institute of Physical Chemistry, Russian Academy of Sciences,
Moscow, Russia (Russ. J. Electrochem., 1999, 35, 434440). It was shown that CER starts to increase in all solutions at around $E=0.1 \mathrm{~V}$ (with respect to reversible hydrogen electrode). In alkaline solutions, the growth of CER increases at higher $\mathrm{KOH}$ concentrations at the expense of adsorption of hydroxyl ions on gold. In acid solutions, the growth of CER decreases with increasing concentration of sulfuric acid. At $E=1.28 \mathrm{~V}$, CER dramatically increases in all solutions. The increase in this case is caused by the formation of primary oxides of gold. Upon reaching $E=1.47 \mathrm{~V}$, the oxides transform into $\mathrm{Au}_{2} \mathrm{O}_{3}$. The CER growth in alkaline and acidic solutions is found to correlate with the electrocatalytic activity of gold in oxidizing hydrazine and reducing bichromate ions. Coverages of gold by adsorbed hydroxyl ions were determined in alkaline solutions, and isotherms of their adsorption plotted for different potentials. See also: L.D. Burke and P.F. Nugent, Gold Bull., 1997, 30, 43-53; 1998, 31, 39-50.

\subsection{Gold Cyanidation using Hydrogen Peroxide}

L. Guzman, M. Segarra, J.M. Chimenos, M.A. Fernandez and F. Espiell of the Department of Physical Chemistry, Universidad Mayor de San Andres, La Paz, Bolivia (Hydrometallurgy, 1999, 52, 21-35) have reported their studies on gold cyanidation, using hydrogen peroxide as an oxidizing agent. They used kinetic experiments, open circuit potential measurements and voltammetry. Small amounts of hydrogen peroxide make the cyanidation rate lower than that in conventional cyanidation, but higher amounts can make the cyanidation rate double. At low temperatures, the process is controlled by a chemical reaction, whereas at higher temperatures, it is controlled by diffusion with higher rates than conventional gold cyanidation at atmospheric pressure. As the presence of hydrogen peroxide displaces the mixed potential of cyanidation to more anodic potentials, where oxygen activity is nil, cyanidation can be performed under conditions of low oxygen pressure. In these conditions, cyanidation is established at transpassive potential regions of gold anodic dissolution and the cyanidation rate is determined by the cyanide concentration. The cyanidation rate can be tripled by adding small amounts of thallium(I) ions to the cyanidation with hydrogen peroxide.

\subsection{In-Situ ATR-IR Study of Water on Gold Electrode Surface}

In research carried out by M. Futamata, Joint Research Center for Atom Technology, National Institute for 
Advanced Interdisciplinary Research, Tsukuba, Japan (Surf. Sci., 1999, 427-428, 179-183), three distinct water species were detected on gold film electrodes deposited on a silicon prism in $1 \mathrm{mM} \mathrm{KX}(\mathrm{X}=\mathrm{F}, \mathrm{Cl}$, $\mathrm{Br}$ or I) solutions using highly sensitive attenuated total reflection (ATR)-IR spectroscopy. Water molecules associated with halide ions at the gold surface give a fairly high frequency for the $\mathrm{O}-\mathrm{H}$ stretching mode at ca $3585 \mathrm{~cm}^{-1}$ with an extremely narrow band width of $50 \mathrm{~cm}^{-1}$, corresponding to fairly weak hydrogen bonding. This band frequency depends not on the halide species but on the alkali metal cations. Furthermore, it was found that the IR background intensity is approximately proportional to the surface coverage of $\mathrm{Br}^{-}$.

\section{ELECTRONICS}

\subsection{Deposition of Passivated Gold Nanoclusters onto Pre-Patterned Substrates}

In studies carried out by A.J. Parker, P.A. Childs, R.E. Palmer and M. Brust, School of Physics and Astronomy, and Nanoscale Physics Research Laboratory, School of Electronic and Electrical Engineering, Semiconductor Devices Group, The University of Birmingham, UK (Appl. Phys. Lett., 1999, 74, 2833-2835), gold nanoclusters, chemically passivated with decanethiol, have been deposited from solution onto silica surfaces pre-patterned by photolithography. After lift-off of the photoresist, preferential cluster accumulation is observed along the edges of the resist structures. Elsewhere on the hydrophilic surface, islands of clusters are observed. By contrast, HF treatment, creating a hydrophobic surface, leads to wetting of the unmasked regions of the substrate by the passivated clusters. See also: G.M. Francis and R.E. Palmer, Gold Bull., 1996, 29, 47-51.

\subsection{A Comparative Assessment of Gold Plating Thickness Required for Stationary Electrical Contacts}

There is considerable interest in the corrosion control of thin gold-plated contact surfaces of consumer electronics products. This originates from the desire to minimize the use of gold and other precious metals, like palladium, and their alloys, without sacrificing reliability. When the application is in adverse environments, however, gold plated contact finishes usually enhance the reliability of the electrical contacts. The failure mechanisms depend strongly on the operating environment and contact plating and are time-dependent processes. Studies have therefore been carried out by S. Ming, M. Pecht and M.A.E. Natishan, CALCE Electronic Products and Systems Consortium, University of Maryland, USA, Microelectron. J., 1999, 30, 217-222, on unloaded gold plated surfaces (unmated and tested under non-operating environmental conditions) to simulate the contact failures induced by corrosion. This article describes the study of loaded electrical contacts with the objective of setting up a comparative model between unloaded and loaded electrical contacts, to improve the understanding of the influence of contact force and applied voltage on the selection of gold layer thickness and finish material. Contact force improves the performance of gold finishes in stationary electrical contacts and decreases significantly the gold plating thickness requirements compared with the unloaded situation because of its effect on suppression of surface film growth. Increased voltage accelerates the growth of surface film and results in the decrease of contact lifetime.

\subsection{Gold Alloy Bonding Wire Having High Strength Suitable for Multipin Semiconductor Devices}

A patent describing this bonding wire was filed by $\mathrm{T}$. Shimizu, Sumitomo Metal Mining Co, Ltd (Japanese Patent 11186314 A2 990709). The wire has coresheath structure, wherein the core is made of a gold alloy containing $0.01-1 \mathrm{wt} \%$ of $\mathrm{Al}$ and/or $\mathrm{Sb}$, and 0.05 $1.5 \mathrm{wt} \%$ of $\mathrm{Rh}$, and the sheath is made of a gold alloy of $99.9999-99 \mathrm{wt} \%$ grade. The sheath gold alloy may be microalloyed with $\mathrm{Ca}, \mathrm{Be}, \mathrm{Ge}, \mathrm{Y}, \mathrm{La}, \mathrm{Ce}, \mathrm{Mg}$, Sn, $\mathrm{In}, \mathrm{Pt}, \mathrm{Pd}$, and/or $\mathrm{Cu}$. The bonding wire, when being heated and molten in air or nitrogen containing $10 \mathrm{wt} \%$ of hydrogen, gives a spherical ball having low hardness, so that the ball does not damage the semiconductor device. See also C.W. Corti, Gold Bull., 1999, 32, 39-47.

\section{MATERIALS SCIENCE}

\subsection{Gold Powder-Polymer Solution Conductive Composite Materials}

This is a review with 46 references written by S. Li of the Institute of Precious Metals, Kunming, P.R. China (Gongneng Cailiao, 1998, 29(Suppl.), 418-421, 429). It covers gold powder-polymer solution conductive composite materials including compositions, conductive mechanisms, and reliability of gold conductive adhesives, and failure mechanisms of gold thick-film conductors. 


\subsection{Normal-Incidence Efficiencies of 4800- Grooves/mm-Ruled Replica Gratings with Multilayer and Gold Coatings in the 125- $325 A$ Wavelengtb Region}

J.F. Seely, T. Watanabe, T. Harada, J.C. Rife and W.R. Hunter of the Naval Research Laboratory, Washington, DC, USA (Appl. Opt., 1999, 38, 1920-1925) have shown that the normal-incidence efficiencies of two 4800 -grooves $/ \mathrm{mm}$ ruled replica gratings, one with a dual-bandpass $\mathrm{Mo} / \mathrm{Si}$ multilayer coating and the other with a gold coating, were measured using synchrotron radiation in the $125-325 \AA$ wavelength region. The peak reflectance of the multilayer coating was $22 \%$ in the first Bragg order near $235 \AA$ and $28 \%$ in the second Bragg order near $126 \AA$. The peak efficiency of the multilayer grating was $2.6 \%$ in the first diffraction order near $225 \AA$ and $0.3 \%$ in the second diffraction order near $125 \AA$. The efficiencies of the multilayer grating were much higher than the corresponding efficiencies of the gold grating. The characterization of the surfaces of the gratings by atomic force microscopy indicated root-mean-square microroughness values in the $5-18 \mu \mathrm{m}^{-1}$ frequency range of $12-20 \AA$ for the multilayer grating and $22-32 \AA$ for the gold grating. Both gratings had bumpy surface features larger than the nominal groove height. The rather large surface roughness and groove irregularities had a detrimental effect on the grating efficiencies.

\section{METALLURGY}

\subsection{Dispersion-Hardened Gold Billet for Manufacture of High-Strengtb Wire Suitable for Microelectronic Circuits}

This process has been patented by Rockwell International (P.D. Krotz, D.D. Hillman and C.N.L. Deblieck, US Patent 5915160 A 990622). A dilute gold alloy containing $0.1-10 \%$ rare-earth metal is processed by: (a) atomizing the alloy into powder with the associated oxidation of the rare-earth metal; (b) sintering the powder to form a billet, especially by hot-isostatic pressing; and (c) canned extrusion of the billet for drawing the wire hardened by oxide dispersion. The process is suitable for manufacture of fine wire from the dilute gold alloy containing yttrium or cerium. The high-strength wire can be drawn to a diameter $<0.001 \mathrm{in}$, especially for a bonding conductor in miniaturized electrical circuits.

\subsection{The Neodymium-Gold Phase Diagram}

The Nd-Au phase diagram has been studied in the 0 to $100 \mathrm{at} \%$ Au composition range by A. Saccone, D. Maccio, S. Delfino and R. Ferro of the Department of Chemistry and Industrial Chemistry, Division of
Inorganic Chemistry and Metallurgy, Genoa, Italy (Metall. Mater. Trans. A, 1999, 30A, 1169-1176). DTA, $X$-ray diffraction, optical microscopy, SEM, and electron probe microanalysis techniques were employed. Six intermetallic phases were identified, the crystallographic structures were determined or confirmed, and the melting behaviour was determined.

Four eutectic reactions were found, at $19.0 \mathrm{at} \% \mathrm{Au}$ and $655^{\circ} \mathrm{C}$, at $63.0 \mathrm{at} \% \mathrm{Au}$ and $1080^{\circ} \mathrm{C}$, at $72.0 \mathrm{at} \% \mathrm{Au}$ and $1050^{\circ} \mathrm{C}$, and, finally, at $91.0 \mathrm{at} \% \mathrm{Au}$ and $795^{\circ} \mathrm{C}$. A catatectic decomposition of the $(\beta-\mathrm{Nd})$ phase, at $825^{\circ} \mathrm{C}$ and ca 1 at $\% \mathrm{Au}$, was also found. The results are discussed and compared with those for the other rare earth-gold systems. A short discussion of the general alloying behaviour of the 'coinage metals' $(\mathrm{Cu}, \mathrm{Ag}$, and $\mathrm{Au}$ ) with the rare-earth metals is also presented.

\section{REFINING}

\subsection{Solvent Extraction of Gold Cyanide with Tributyl Phosphate and Additive in Aqueous Phase}

A new solvent extraction system for gold cyanide has been described by J. Chen, L. Zhu, Y. Jing, X. Pang and K. Huang, Institute of Precious Metals, Kunming, P.R. China (Precious Met., 1998, 22, 65-74). The system contains additives (SP or ST; molar ratio of $\mathrm{Au}(\mathrm{CN})_{2}{ }^{-}$ :additive $=1: 1$ ) and was studied at various $\mathrm{pH}$ values, gold concentrations, TBP concentrations, temperatures, equilibration times, molar ratios of $\mathrm{Au}(\mathrm{CN})^{2-}$ : additive, phase ratios (A/O) etc. The extraction system was tested on real feed solutions obtained from a mine. The results show that $\mathrm{Au}(\mathrm{CN})^{2-}$ could be quantitatively and selectively extracted in a wide range of $\mathrm{pH}$ (ca 2-12). The extraction mechanism is discussed.

\subsection{Solvent Extraction of Gold(III) by the Cbloride Salt of the Tertiary Amine Hostarex A327. Estimation of the Interaction Coefficient Between $\mathrm{AuCl}^{4}$ and $\mathrm{H}^{+}$}

The equilibrium distribution of gold(III) between hydrochloric acid and the chloride salt of the amine Hostarex A327 in n-decane has been studied by S. Martinez, A.M. Sastre and F.J. Alguacil of the Ciudad Universitaria, Centro Nacional de Investigaciones Metalurgicas (CSIC), Madrid (Hydrometallurgy, 1999, $52,63-70)$. The extraction reaction is exothermic $(\Delta \mathrm{H}$ $=-22.9 \mathrm{~kJ} / \mathrm{mol}$ ), and the extraction equilibrium constant depends on the ionic strength. From this dependency it was estimated that the interaction coefficient $\left(\mathrm{AuCl}^{4-}, \mathrm{H}^{+}\right)$is 0.26 . 